\title{
LA VIVIENDA COLECTIVA DE LA MODERNIDAD EN TIEMPOS DE COVID19. APORTACIONES DEL PARADIGMA HABITACIONAL
}

A habitação coletiva da modernidade em tempos de COVID19. Contribuições do paradigma habitacional

Modern collective housing of modernity in times of COVID-19. Contributions of the housing paradigm

Pablo Francisco Gómez Porter

Profesor Titular. Tiempo Completo. Facultad de

Arquitectura. Universidad Nacional Autónoma de México.

Ciudad de México, México.

gporter@unam.mx

https://orcid.org/0000-0003-4963-4410

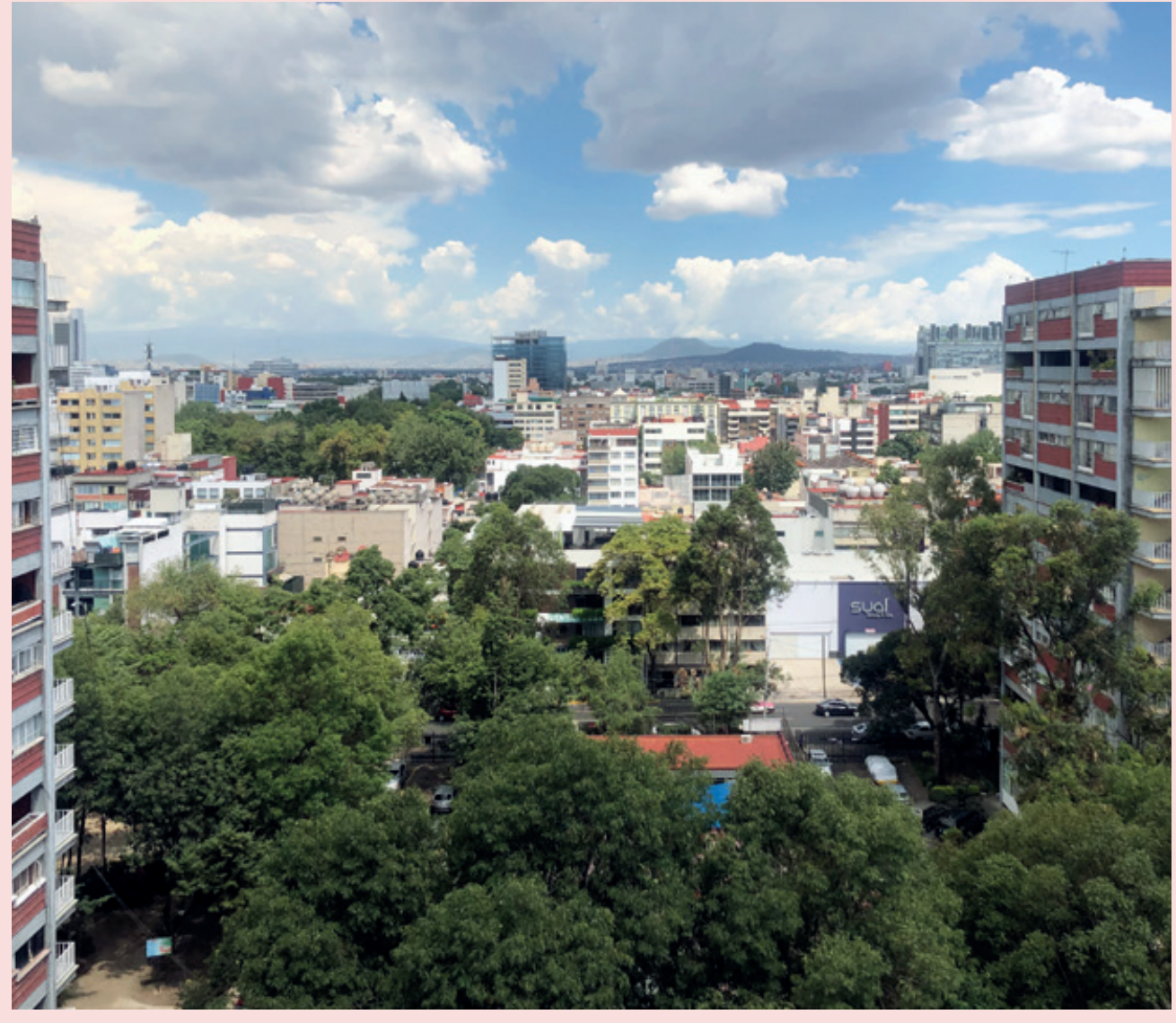

Financiamiento Universidad Nacional Autónoma de México.
Visuales desde las torres de departamentos del Centro Urbano Presidente Alemán (CUPA). Es posible apreciar los jardines interiores del conjunto, asi como panorámicas de la Ciudad de México.

Fuente: Fotografía del autor, abril de 2021 . 


\title{
RESUMEN
}

La habitación colectiva de la modernidad generó un paradigma de diseño urbano-arquitectónico, que incorporaba espacios cuyo diseño fomentaba, de acuerdo con los arquitectos de la modernidad, salud e higiene mediante la circulación de aire puro, iluminación y ventilación naturales al interior de las viviendas, al igual que en los espacios compartidos y de circulación característicos de esa tipología habitacional. Esos elementos de diseño parecen ser útiles en la reducción de contagios del virus SarsCov2 y que actualmente afecta al mundo entero. Para verificar este supuesto, se realizó un trabajo de campo y en línea con habitantes del Centro Urbano Presidente Alemán (CUPA), conjunto representativo de la modernidad arquitectónica en la Ciudad de México. Mediante reconstrucciones volumétricas y cuestionarios en línea se analizaron los elementos de diseño que materializan los ideales modernos orientados a garantizar espacios exteriores e interiores sanos; se evaluó la utilidad de los equipamientos colectivos, espacios de circulación y el diseño de las cuatro tipologías de vivienda que tiene el conjunto. Los resultados del estudio y la ausencia de casos de COVID19 en el CUPA, ayudan a demostrar la validez que recobra la arquitectura moderna en la pandemia mundial, así como la importancia de las lecciones del pasado para integrar nuevos paradigmas de diseño para una arquitectura post-Covid.

Palabras Clave: Modernidad, higiene, equipamiento comunitario, conjuntos habitacionales, áreas verdes

\section{RESUMO}

A habitação coletiva da modernidade gerou um paradigma de desenho urbano-arquitetônico que incorporava espaços cujo design promovia, de acordo com os arquitetos da modernidade, saúde e higiene por meio da circulação de ar puro, iluminação e ventilação naturais no interior das casas, bem como nos espaços compartilhados e de circulação característicos desta tipologia habitacional. Esses elementos de design parecem ser úteis na redução da disseminação do vírus SarsCov2, que atualmente afeta o mundo inteiro. Para verificar esta hipótese, realizou-se um trabalho de campo e on-line com moradores do Centro Urbano Presidente Alemán (CUPA), um conjunto representativo da modernidade arquitetônica localizado na Cidade do México. Mediante reconstruções volumétricas e questionários on-line, foram analisados os elementos de design que incorporam os ideais modernos que visam garantir espaços exteriores e interiores saudáveis; Foi avaliada a utilidade dos equipamentos coletivos, dos espaços de circulação e do desenho dos quatro tipos de habitação existentes no conjunto. Os resultados do estudo e a ausência de casos de COVID19 no CUPA ajudam a demonstrar a legitimidade que a arquitetura moderna recupera durante esta pandemia de escala global, bem como a importância das lições do passado para integrar novos paradigmas de design em uma arquitetura pós-Covid.

Palavras-Chave: Modernidade, higiene, equipamentos comunitários, conjuntos habitacionais, áreas verdes

\begin{abstract}
Modern collective housing generated an urban-architectural design paradigm, which incorporated spaces whose design promoted, following modern architects, health and hygiene through the circulation of clean air, natural lighting and ventilation inside dwellings, as well as in the shared spaces and those where people move around, characteristic of this housing typology. These design elements seem to be useful to reduce the spread of the SarsCov2 virus, that is currently affecting the entire world. Field and online work was carried out with the inhabitants of the CUPA, a housing complex representative of modern architecture in Mexico City, to verify this assumption. Using volumetric reconstructions and online questionnaires, the design elements that embody modern ideals, aimed at ensuring healthy indoor and outdoor spaces, were analysed. The usefulness of the collective facilities, public spaces and the design of the four housing typologies found within the, were assessed. The results of the study and the absence of COVID-19 cases in CUPA help to prove the validity that modern architecture has regained during the global pandemic, as well as the importance of the lessons from the past to integrate new design paradigms for a post-Covid architecture.
\end{abstract}

Keywords: Modernity, hygiene, community facilities, housing complexes, green areas 


\section{INTRODUCCIÓN}

La habitación colectiva de la modernidad es un legado de las discusiones de los Congresos Internacionales de Arquitectura Moderna - CIAM - en torno a la vivienda y al desarrollo de las ciudades a partir de la habitación concebida como su célula básica (CIAM, 1933). Esas contribuciones, que proponían soluciones desde la arquitectura y el urbanismo a las problemáticas urbanas del momento, quedaron plasmadas en la Carta de Atenas de 1933.

La Carta proponía agrupar vivienda en torres de gran altura aprovechando el terreno disponible para desarrollar extensas áreas verdes, comercios, equipamiento colectivo, zonas deportivas, centros de enseñanza e incluso guarderías, o maternidades, para el cuidado de los niños. Así, los moradores no tendrían la necesidad de desplazarse a otras áreas de las ciudades para el desarrollo de sus actividades esenciales. Las células de habitación deberían garantizar desde su diseño, al igual que los espacios colectivos, la entrada de luz y ventilación naturales generando al interior espacios sanos, limpios, ventilados y transparentes con lo que se pretendía abatir la propagación de enfermedades que, para entonces, acompañaban a la casa tugurizada; surgía el paradigma de la súper manzana de habitación.

Estos preceptos de diseño fueron preconizados por Le Corbusier en todo el mundo y materializados en la célebre unidad de Marsella que, al ser testimonio del pensamiento moderno, fue inscrita en 2016, junto con otras 16 obras del arquitecto suizo, en la Lista del Patrimonio Mundial como contribución excepcional al Movimiento Moderno (UNESCO, 2020), bajo los criterios de elegibilidad (i),(ii), (vi) de la Convención del Patrimonio Mundial y Cultural con los que se realizó la declaración de su Valor Universal Excepcional (UNESCO, 1972; 2008).

Sin embargo, América Latina fue depositaria de la mayor cantidad de estas obras donde se edificaron exponentes de gran escala que en la actualidad son enclaves que se distinguen en ciudades de la región y cuyo desarrollo fue impulsado desde el Estado. Los gobiernos de las repúblicas latinoamericanas de la mitad del siglo $X X$ encontraron en el paradigma de la súper manzana de habitación una herramienta ideal para su aceptación y legitimación sociales (Sambricio, 2012).

En México, la primera unidad de habitación que se edificó atendiendo a esos postulados de diseño fue el Centro Urbano Presidente Alemán (CUPA), ubicado al sur de la capital mexicana, diseñado por el arquitecto Mario Pani y construido entre 1947 y 1949 con el auspicio de la Dirección General de Pensiones Civiles, que hoy es el Instituto de Seguridad y Servicios Sociales para los Trabajadores del Estado (ISSSTE). Se desarrolla en un terreno de 40,000 $\mathrm{m}^{2}$ de los cuales solo el $20 \%$ se ocupa como área de desplante para inmuebles construidos, mientras que el $80 \%$ restante se destina a zonas deportivas y jardines; en la planta de los edificios se ubican locales comerciales y de servicios.

El conjunto cuenta con 1080 viviendas que se agrupan en seis torres de 12 niveles y seis edificios pequeños de tres niveles (Pani, 1950, pp. 268-269), dispone de cuatro tipologías diferentes de habitación 
Figura 1

Ventanales de los departamentos

agrupados en torres de 12 niveles en el CUPA.

Fuente: fotografia del autor (2020).

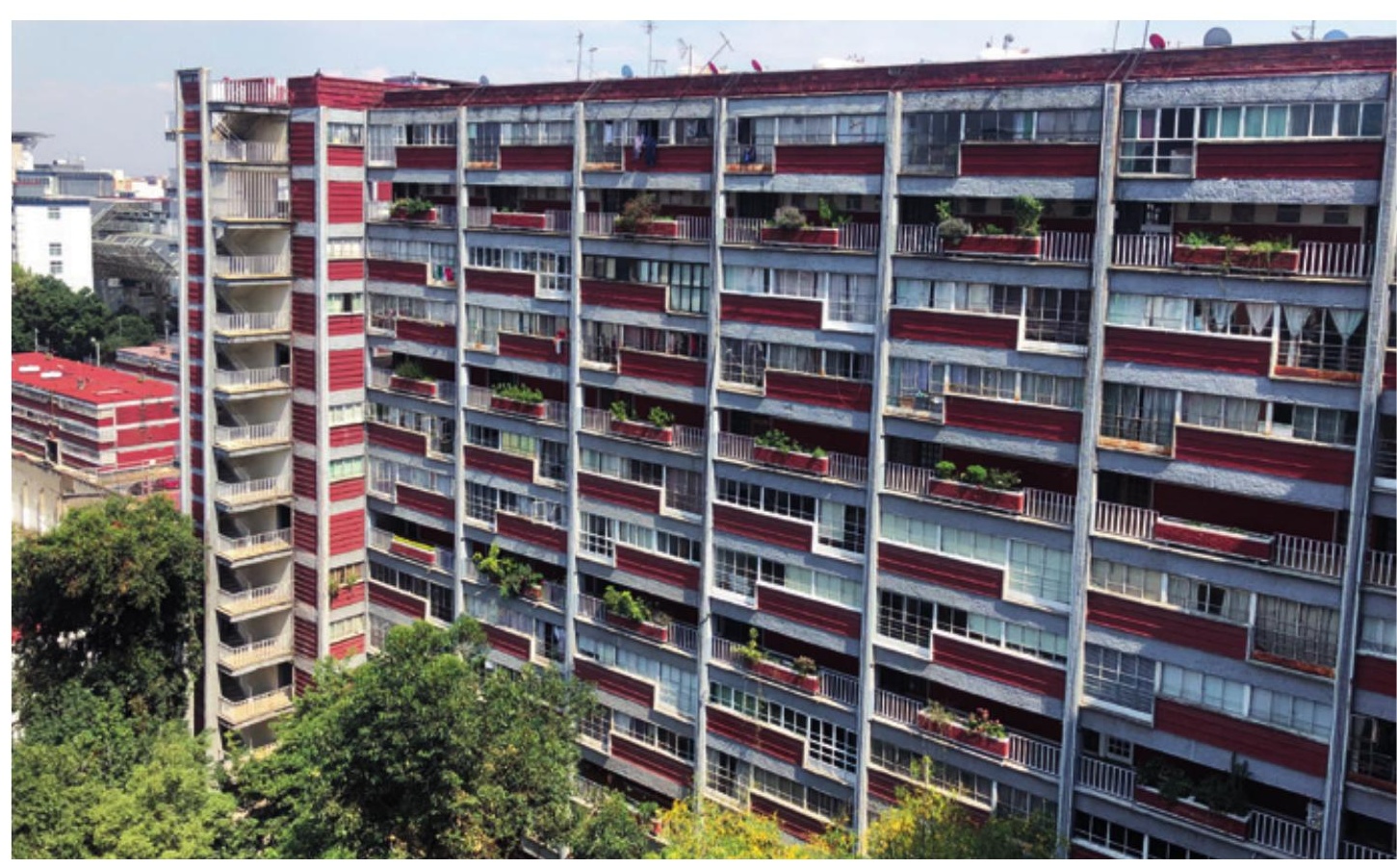

(Pani, 1952, pp. 27-34) en cuyo interior se materializan los ideales de transparencia e higiene impulsadas desde la modernidad (Muxí, 2020, p. 7) con la presencia de ventanales corridos que permiten la entrada de luz natural al interior de cada célula habitacional [Figura I].

Al inicio de la década de los 70 del siglo XX, este modelo de habitación evidenció problemas en la dimensión de su gestión (Villavicencio, 2006) y en la coexistencia entre los propios habitantes. Asimismo, en 1972, la demolición del conjunto Pruitt Iggoe de San Luis Missouri, obra de Minuro Yamasaki, dio pie para que Charles Jeckens señalara que con ese hecho había muerto el movimiento (Montaner, 2015, pp. 158- 159). Sin embargo, la pandemia actual ha obligado a replantear el diseño arquitectónico, así como a analizar, e incluso retomar, paradigmas de diseño legados del pasado que pretendían, entre otras cosas, promover espacios sanos y limpios mediante la ventilación, circulación de aire y entrada de luz natural.

En este marco, el artículo presente analiza la hipotética utilidad de un caso de estudio representativo de la modernidad como lo es el CUPA en México. Autores como Morawska han presentado estudios que demuestran que el medio más eficiente de transmisión del virus son los aerosoles que exhalamos al hablar y que sobreviven en espacios cerrados y sin ventilación; en cambio en espacios abiertos y ventilados las posibilidades de contagio se reducen considerablemente (Morawska y Cao, 2020). 


\section{METODOLOGÍA}

Tabla 1

Grupos de población del CUPA por rango de edades. Se resalta el grupo con mayor cantidad de personas.

Fuente. Elaboración del autor con base en los datos del Inventario Nacional de Vivienda (INEGI, 2016) (https://Www. inegi.org.mx/app/mapa/inv/)

\begin{tabular}{|l|l|c|}
\hline \multicolumn{1}{|c|}{$\begin{array}{c}\text { Grupos de } \\
\text { población }\end{array}$} & \multicolumn{1}{|c|}{$\mathrm{N}^{\circ}$} & \multicolumn{1}{c|}{$\%$} \\
\hline $\begin{array}{l}\text { Población de 0 a } \\
14 \text { años }\end{array}$ & 245 & 11,10607434 \\
\hline $\begin{array}{l}\text { Población de 15 a } \\
29 \text { años }\end{array}$ & 462 & 20,94288305 \\
\hline $\begin{array}{l}\text { Población de } 30 \text { a } \\
59 \text { años }\end{array}$ & 900 & 40,79782412 \\
\hline $\begin{array}{l}\text { Población de } 60 \text { y } \\
\text { más años }\end{array}$ & 440 & 19,9456029 \\
\hline $\begin{array}{l}\text { Población con } \\
\text { discapacidad }\end{array}$ & 152 & 6,890299184 \\
\hline TOTAL & 2199 & 99,68268359 \\
\hline
\end{tabular}

Para evaluar la posible utilidad del diseño de la súper manzana de habitación en la disminución de contagios aéreos del COVIDI9, a partir del análisis de un caso de estudio paradigmático como el CUPA, se realizaron modelos tridimensionales de todo el conjunto y de cada una de sus cuatro tipologías de vivienda a partir de los planos originales publicados en el libro Los multifamiliares de pensiones (Pani, 1952, pp. 27-34) y la revista Arquitectura México (Pani, 1950, pp. 268269), verificando la información con recorridos en sitio. El modelaje tridimensional del conjunto consideró los comercios de planta baja, jardines y áreas verdes que rodean los edificios de vivienda acomodados en el terreno a'redent (De Garay, 2004).

El análisis espacial se complementó y comparó con cuestionarios aplicados a habitantes, las preguntas se diseñaron para evaluar la eficiencia de los atributos del diseño arquitectónico que, hipotéticamente, ayudan a reducir las cadenas de contagio con aerosoles en espacios de uso colectivo y al interior de las viviendas. Para determinar la población objetivo de la encuesta se examinaron los perfiles poblacionales indicados en el Inventario Nacional de Vivienda (INEGl, 2016), en el cual se indica que el sector poblacional predominante tiene un rango de edad que oscila entre 30 y 59 años [Tabla I].

Este sector conforma la población económicamente activa, de modo que un bloque de preguntas evaluó la compatibilidad de actividades laborales con las del habitar para quienes pueden trabajar desde casa. Además, los integrantes del segmento poblacional referido son usuarios asiduos de las redes sociales con que cuentan los vecinos del conjunto para comunicarse, por lo que fue posible aplicarles una encuesta en dos formularios de Google. La plataforma digital permite graficar los resultados en tiempo real, de manera de evitar la interacción física para aplicar los cuestionarios, evitando así posibles contagios.

El primer cuestionario se enfocó en los comercios y espacios colectivos; abordó la utilidad de los productos que ahí se ofrecen para identificar si son suficientes para abastecer productos de la canasta básica entre los moradores, o si es necesario salir de la unidad para abastecerse. Para reconocer los tipos de comercio e incluirlos en la encuesta, se revisaron datos de actividad económica y comercial del inventario de vivienda (INEGI, 2016); información que se verificó mediante recorridos de campo. Los giros comerciales disponibles en la planta baja del CUPA son: lavandería, mercado de alimentos, carnicería, tienda de abarrotes, farmacia, panadería, tortillería, zapatería, restaurante (venta de alimentos preparados), papelería y tintorería.

En esta misma sección se preguntó a los habitantes si han usado los jardines que rodean el CUPA durante la pandemia y si se sienten seguros de circular en ellos sin temor de contagiarse. Preguntas similares se hicieron en relación a los pasillos de circulación perimetrales que dan acceso a las viviendas localizadas en torres. La sección se complementó al consultar si se ha tenido noticias de contagios de COVID al interior de la unidad de habitación [Tabla 2]. 
Tabla 2

Preguntas del cuestionario aplicado a los habitantes del CUPA para áreas comunes y locales comerciales.

Fuente. Elaboración del autor (2020).

\section{Habitar el CUPA durante COVID (tiendas y jardines)}

\section{Comercios y abastos}

1. ¿Los productos que se venden en los locales comerciales del CUPA te han permitido abastecer la canasta básica durante la pandemia?

\section{a) Sí}

b) No

2. ¿Has tenido que salir del CUPA durante la pandemia para comprar productos de consumo básico tales como alimentos, medicamentos, papel higiénico, jabón productos de limpieza o aseo personal?

3. ¿Cuál es el tipo de comercio que hay en el CUPA que mayor utilidad te ha ofrecido durante la pandemia? ¿Por qué? (respuesta abierta)

a) Sí

b) No

¿Por qué? (respuesta abierta)

a) Lavanderías

b) Mercado

c) Carnicerías

d) Tiendas de abarrotes

e) Farmacia

f) Panadería

g) Farmacia

h) Tortillerías

i) Zapatería

j) Restaurantes

k) Papelería

l) Tortas (Don Polo)

m) Tintorería

n) Todos los anteriores

\begin{tabular}{|c|c|}
\hline \multicolumn{2}{|l|}{ Áreas verdes } \\
\hline \multirow{3}{*}{$\begin{array}{l}\text { 1. ¿Has utilizado los jardines del CUPA con } \\
\text { motivos recreativos durante la pandemia? }\end{array}$} & a. Sí \\
\hline & b. No \\
\hline & ¿Por qué? (respuesta abierta) \\
\hline \multirow{3}{*}{$\begin{array}{l}\text { 2. ¿Cuándo caminas por los jardines del } \\
\text { CUPA tienes miedo de contagiarte de } \\
\text { COVID? }\end{array}$} & a. Sí \\
\hline & b. No \\
\hline & ¿Por qué? (respuesta abierta) \\
\hline \multirow[t]{4}{*}{ Tipo de departamento que habitas: } & a. De pasillo (en torre) \\
\hline & b. De esquina (en torre) \\
\hline & c. Edificio B, D o F (en torre) \\
\hline & d. Edificios chiquitos \\
\hline \multicolumn{2}{|c|}{ Pasillos de circulación perimetrales en torres de departamento } \\
\hline \multirow{3}{*}{$\begin{array}{l}\text { 1. ¿Has utilizado los pasillos del CUPA con } \\
\text { motivos recreativos durante la pandemia? } \\
\text { (no solo para ingresar a tu vivienda) }\end{array}$} & a. Sí \\
\hline & b. No \\
\hline & ¿Por qué? \\
\hline \multirow{3}{*}{$\begin{array}{l}\text { 2. ¿Cuándo caminas por los pasillos del } \\
\text { CUPA tienes miedo de contagiarte de } \\
\text { COVID? }\end{array}$} & c. Sí \\
\hline & d. No \\
\hline & ¿Por qué?(respuesta abierta) \\
\hline \multicolumn{2}{|l|}{ Casos de COVID en el CUPA } \\
\hline \multirow{3}{*}{$\begin{array}{l}\text { 1. ¿Has sabido de algún contagio o caso } \\
\text { de COVID dentro del CUPA? }\end{array}$} & a. Sí \\
\hline & b. No \\
\hline & c. Prefiero no decirlo \\
\hline
\end{tabular}


Tabla 3

Nombres y características generales

de las cuatro tipologías de

vivienda del CUPA. Para el caso del

departamento en esquina (tipo B-C),

la variación es mínima y consiste en

la posibilidad de ocupar una covacha

de servicio junto a la entrada del

departamento.

Fuente. Elaboración del autor con

base en Pani (1950, p. 268).

\begin{tabular}{|c|c|c|c|c|c|c|}
\hline $\begin{array}{c}\text { Nomenclatura } \\
\text { original }\end{array}$ & $\begin{array}{l}\text { Número de } \\
\text { deptos. }\end{array}$ & $\begin{array}{l}\text { Tipo de edificio donde } \\
\text { se ubica }\end{array}$ & $\begin{array}{l}\text { Nombre coloquial con } \\
\text { que se le conoce }\end{array}$ & M2 & $\begin{array}{l}\text { Niveles de } \\
\text { la vivienda }\end{array}$ & $\begin{array}{c}\text { Encuestas } \\
\text { aplicadas/tipo } \\
\text { depto. }\end{array}$ \\
\hline Tipo A & 672 & Torre & De pasillo & 48 & 2 & 145 \\
\hline Tipo B-C & 192 & Torre & De esquina & 80 & 1 & 58 \\
\hline Tipo D & 72 & Torre (norte-sur) & Edificio $B, D \circ F$ & 110 & 2 & 36 \\
\hline Tipo E & 144 & Edificio tres niveles & Chiquito & 57 & 1 & 52 \\
\hline Total & 1080 & & & & Total & 291 \\
\hline
\end{tabular}

En el segundo cuestionario se incluyeron preguntas relativas a la vivienda, concretamente cuatro diferentes, una para cada tipo de vivienda. En los textos y planos publicados por Pani, las tipologías de departamento se clasifican por letra, tres de las cuales se agrupan en edificios de 12 niveles, que en la actualidad poseen nombres coloquiales con los que son identificados por los habitantes [Tabla 3], por lo cual las encuestas respetaron dichas denominaciones.

Los conceptos que se abordaron en los cuatro cuestionarios corresponden a las condiciones al interior de la vivienda en relación con los elementos de diseño propios de la modernidad que materializan preceptos de higiene, tales como la utilidad de las ventanas para ventilar e iluminar la totalidad de la vivienda, así como la compatibilidad de actividades propias del habitar con las de trabajar para quienes tienen la oportunidad de laborar desde casa [Tabla 4].

Todos los cuestionarios fueron de opción múltiples, aunque se dio espacio para señalar respuestas libremente con el fin de que los encuestados pudieran manifestar cualquier situación no considerada en las preguntas. El cuestionario estuvo abierto durante tres semanas, tiempo en el que se recabaron 29I primeras respuestas; de él se derivaron 145 para el departamento tipo A (de pasillo), 58 para el tipo B-C (de esquina), 36 para el tipo D (edificio norte-sur) y 52 para el tipo D (edificio chiquito). Finalmente, en la página oficial del Gobierno de la Ciudad de México se buscaron registros de casos COVID registrados en el CUPA en mapas interactivos y en datos estadísticos disponibles por colonia. La información oficial obtenida se contrastó con las respuestas recabadas en los cuestionarios.

Tabla 4

Resultados del cuestionario aplicado a habitantes para evaluar la utilidad de locales comerciales, jardines y zonas de circulación colectivas del CUPA durante la pandemia. Las respuestas que mayor cantidad de menciones tuvieron entre los entrevistados se resaltan para facilitar su identificación. * Los comentarios de las respuestas abiertas se incorporaron en la presentación de resultados. Fuente: Elaboración del autor (2021). 
Habitar el CUPA durante COVID (comercios, jardines y circulaciones) 291 encuestas aplicadas

\begin{tabular}{|c|c|c|c|}
\hline \multicolumn{2}{|l|}{ Comercios y abastos } & \multirow{2}{*}{\begin{tabular}{|l|} 
Respuestas \\
seleccionadas
\end{tabular}} & \multirow{2}{*}{\begin{tabular}{|l|} 
Porcentaje \\
87,62886598
\end{tabular}} \\
\hline 1. ¿Los productos que se venden en los locales & a) Sí & & \\
\hline cer la canasta básica durante la pandemia? & b) $\mathrm{No}$ & 36 & 12,37113402 \\
\hline \multirow{2}{*}{$\begin{array}{l}\text { 2. ¿Has tenido que salir del CUPA durante la } \\
\text { pandemia para comprar productos de consumo } \\
\text { básico tales como alimentos, medicamentos, } \\
\text { papel higiénico, jabón, productos de limpieza o } \\
\text { aseo personal? }\end{array}$} & a) Sí & 36 & 12,37113402 \\
\hline & b) $\mathrm{No}$ & 255 & 87,62886598 \\
\hline \multirow{12}{*}{$\begin{array}{l}\text { 3. ¿Cuál es el tipo de comercio que hay en el } \\
\text { CUPA que mayor utilidad te ha ofrecido durante } \\
\text { la pandemia? }\end{array}$} & a) Lavanderías & 5 & 1,718213058 \\
\hline & b) Mercado & 73 & 25,08591065 \\
\hline & c) Carnicería & 8 & 2,749140893 \\
\hline & d) Tiendas de abarrotes & 86 & 29,5532646 \\
\hline & e) Farmacia & 63 & 21,64948454 \\
\hline & f) Panadería & 2 & 0,687285223 \\
\hline & g) Tortillerías & 23 & 7,903780069 \\
\hline & h) Zapatería & 2 & 0,687285223 \\
\hline & i) Restaurantes & 10 & 3,436426117 \\
\hline & j) Papelería & 6 & 2,06185567 \\
\hline & k) Tortas (Don Polo) & 11 & 3,780068729 \\
\hline & I) Tintorería & 2 & 0,687285223 \\
\hline \multicolumn{2}{|l|}{ Áreas verdes } & $\begin{array}{l}\text { Respuestas } \\
\text { seleccionadas }\end{array}$ & Porcentaje \\
\hline \multirow{2}{*}{$\begin{array}{l}\text { 1. ¿Has utilizado los jardines del CUPA con } \\
\text { motivos recreativos durante la pandemia? }\end{array}$} & a. Sí & 263 & 90,37800687 \\
\hline & b. No & 28 & 9,621993127 \\
\hline \multirow{2}{*}{$\begin{array}{l}\text { 2. ¿Cuándo caminas por los jardines del CUPA } \\
\text { tienes miedo de contagiarte de COVID?* }\end{array}$} & a. Sí & 9 & 3,09278351 \\
\hline & b. No & 282 & 96,9072165 \\
\hline \multirow[t]{4}{*}{ Tipo de departamento que habitas: } & a. De pasillo (en torre) & 145 & 49,82817869 \\
\hline & b. De esquina (en torre) & 58 & 19,93127148 \\
\hline & $\begin{array}{l}\text { c. Edificio B, D o F (en } \\
\text { torre) }\end{array}$ & 36 & 12,37113402 \\
\hline & d. Edificios chiquitos & 52 & 17,86941581 \\
\hline \multicolumn{2}{|c|}{ Pasillos de circulación perimetrales en torres de departamento } & $\begin{array}{l}\text { Respuestas } \\
\text { seleccionadas }\end{array}$ & Porcentaje \\
\hline \multirow{2}{*}{$\begin{array}{l}\text { 1. ¿Has utilizado los pasillos del CUPA con } \\
\text { motivos recreativos durante la pandemia? (no } \\
\text { solo para ingresar a tu vivienda) }\end{array}$} & a. Sí & 264 & 90,72164948 \\
\hline & b. No & 27 & 9,278350515 \\
\hline \multirow{2}{*}{$\begin{array}{l}\text { 2. ¿Cuando caminas por los pasillos del CUPA } \\
\text { tienes miedo de contagiarte de COVID? }\end{array}$} & c. Sí & 25 & 8,591065292 \\
\hline & d. No & 266 & 91,40893471 \\
\hline \multicolumn{2}{|l|}{ Casos de COVID en el CUPA } & $\begin{array}{l}\text { Respuestas } \\
\text { seleccionadas }\end{array}$ & Porcentaje \\
\hline \multirow{3}{*}{$\begin{array}{l}\text { 1. ¿Has sabido de algún contagio o caso de } \\
\text { COVID dentro del CUPA? }\end{array}$} & a. Sí & 1 & 0,343642612 \\
\hline & b. No & 290 & 99,65635739 \\
\hline & c. Prefiero no decirlo & 0 & 0 \\
\hline
\end{tabular}


RESULTADOS

\section{ÁREAS COMUNES}

Figura 2

Volumetría del Centro Urbano Presidente Alemán. Los jardines que rodean las torres de vivienda y que ocupan la mayor proporción del área de desplante se aprecian en color verde.

verde. de Jorge Rendón, de Jorge Rendón, de acuerdo con los planos mostrados en Arquitectura Mexico (Pani, 1952, p. 265) $y$ en los recorridos de campo realizados por el autor.
Los datos mostrados en la Tabla 4 permiten identificar que los comercios y servicios disponibles al interior del conjunto habitacional han resultado suficientes para garantizar el abasto de productos de la canasta básica entre sus residentes. A su vez, los supermercados cercanos también han resultado una opción para la compra de víveres, aunque son utilizados con menor frecuencia entre los 29| entrevistados. Los comercios que mayor utilidad han tenido son los destinados a venta de alimentos (tiendas de abarrotes y mercados), seguido de las farmacias que ofrecen medicamentos, productos de aseo personal y alimentos no pereceros.

Los jardines, que ocupan la mayor parte del predio [Figura 2], se constituyeron durante la pandemia como los necesarios espacios de recreación y de alivio del confinamiento caracterizados por ser ambientes naturales y ventilados. Por lo que, en términos de transmisión aérea del virus, son espacios con menor riesgo de contagio [Tabla 4]; adicionalmente son extensiones de la propia vivienda.

Los resultados referentes a los pasillos de circulación perimetrales que dan acceso a las viviendas en torre [Tabla 4], evidenciaron que la mayor parte de los encuestados los utilizan -además de su función intrínseca de acceso y circulación- para realizar caminata recreativa en los periodos de descanso de la jornada laboral, para quienes trabajan desde casa. Las visuales panorámicas que desde ahí se tiene hacia los jardines interiores del CUPA y a la ciudad, constituyen atributos que mejoran significativamente la experiencia de uso recreativo en esas áreas de circulación [Figura 3].

Así también, las encuestas revelan que la extensión de esos pasillos permite mantener la sana distancia entre usuarios. Una vez más,

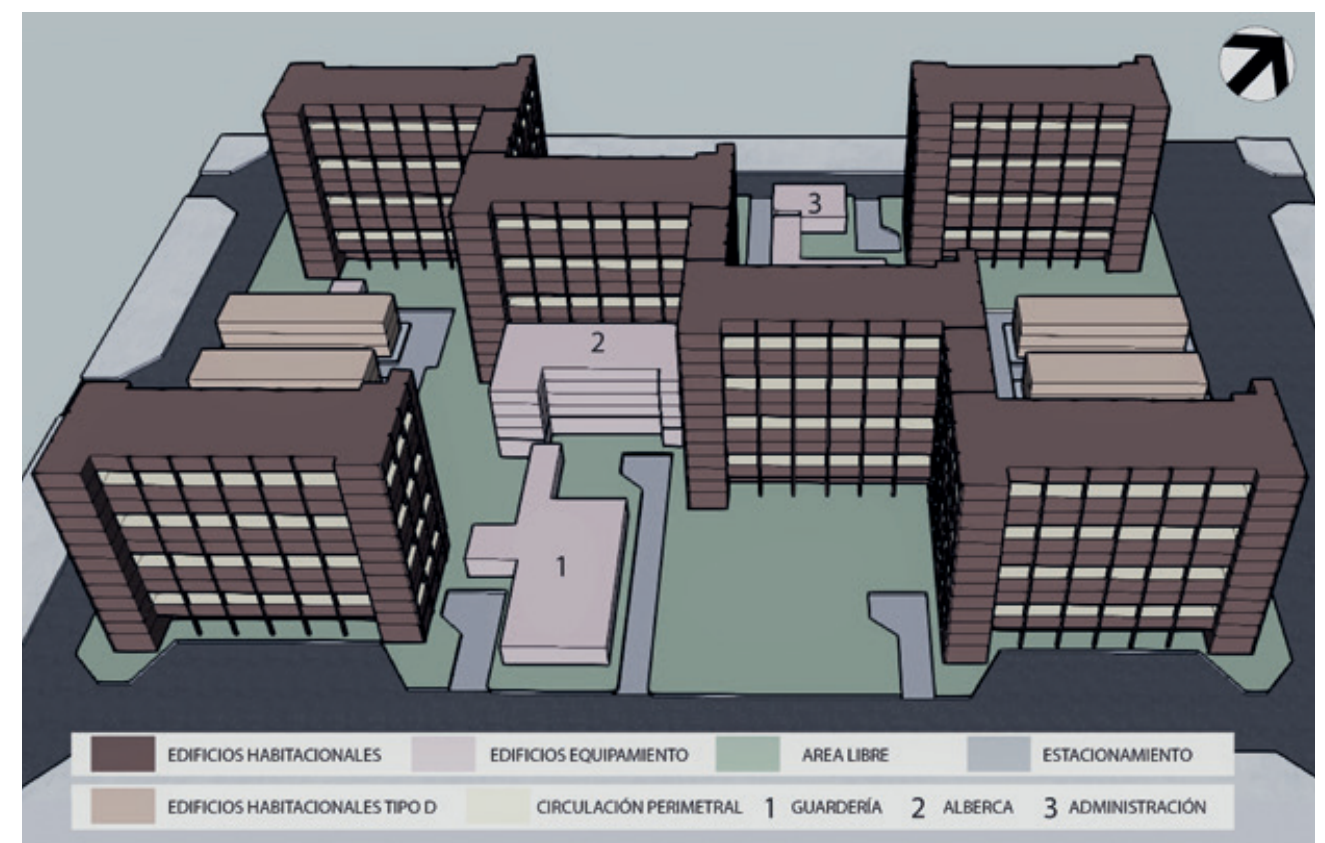


Figura 3

Pasillos de

circulación

perimetrales para

acceso a viviendas

en torre.

Fuente: Fotografia

del autor.

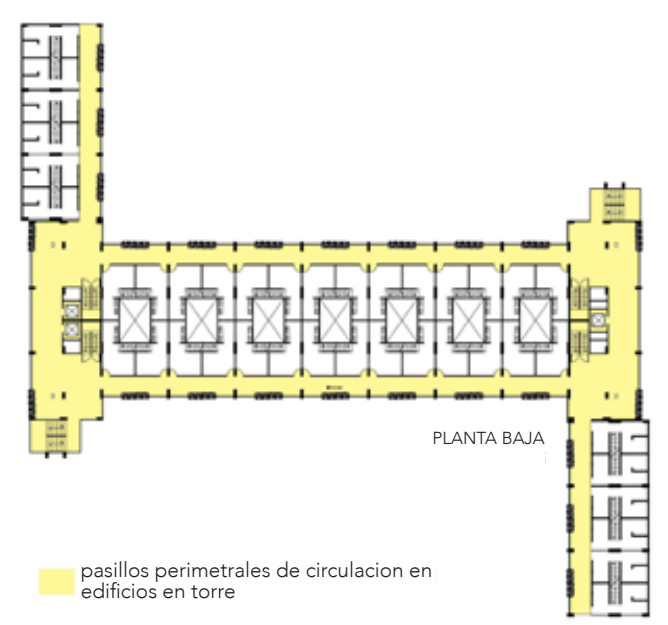

se observa que a partir de la configuración espacial es posible definir espacios con menor riesgo de transmisión aérea del virus. Esta seguridad que se da en los espacios de circulación abiertos [Figura 3] se refuerza con el uso de cubrebocas por parte de los usuarios; información que se verificó con los recorridos de campo.

La búsqueda de casos COVIDI9 en la plataforma oficial del gobierno local arrojó que no se han identificado contagios en el CUPA ni en mapa interactivo, ni en las gráficas por colonia (Gobierno CDMX, 2020). De igual forma, la mayor parte de los 29 I encuestados señalaron no saber de ningún contagio al interior de la unidad habitacional a pesar de estar ubicados frente al Hospital 20 de noviembre, que atiende pacientes COVID y causa temor de posibles contagios entre algunos habitantes, de acuerdo con los comentarios recibidos en las encuestas.

Quienes afirmaron trabajar fuera de casa señalaron que al regresar al CUPA tienen la sensación de estar protegidos del virus porque los espacios para ingresar a las viviendas son abiertos, permitiendo la circulación del aire [Tabla 4]. Quienes indicaron lo contrario argumentaron que el temor se deriva de la cercanía con el hospital: afirman que hay riesgo de contagios, así como por la limpieza en los jardines que son utilizados por otros vecinos para que sus perros orinen y defequen, pero no recogen las heces, lo que refiere a una compleja convivencia vecinal característica de este hábitat urbano (Duahu y Giglia, 2008, p. 294) y problemáticas de gestión condominal que también acompañan este conjunto a partir de los cambios en sus esquemas de propiedad internos (Gómez, 2020). 


\section{VIVIENDAS}

\section{Figura 4}

Lámina con planta

arquitectónica

y volumetría,

departamento tipo

Fuente: Elaboración

de Raúl Cerezo

(2021).

Figura 5

Lámina con planta

arquitectónica

y volumetría,

y volumetría,

B-C.

Fuente: Elaboración

de Raúl Cerezo

(2021).
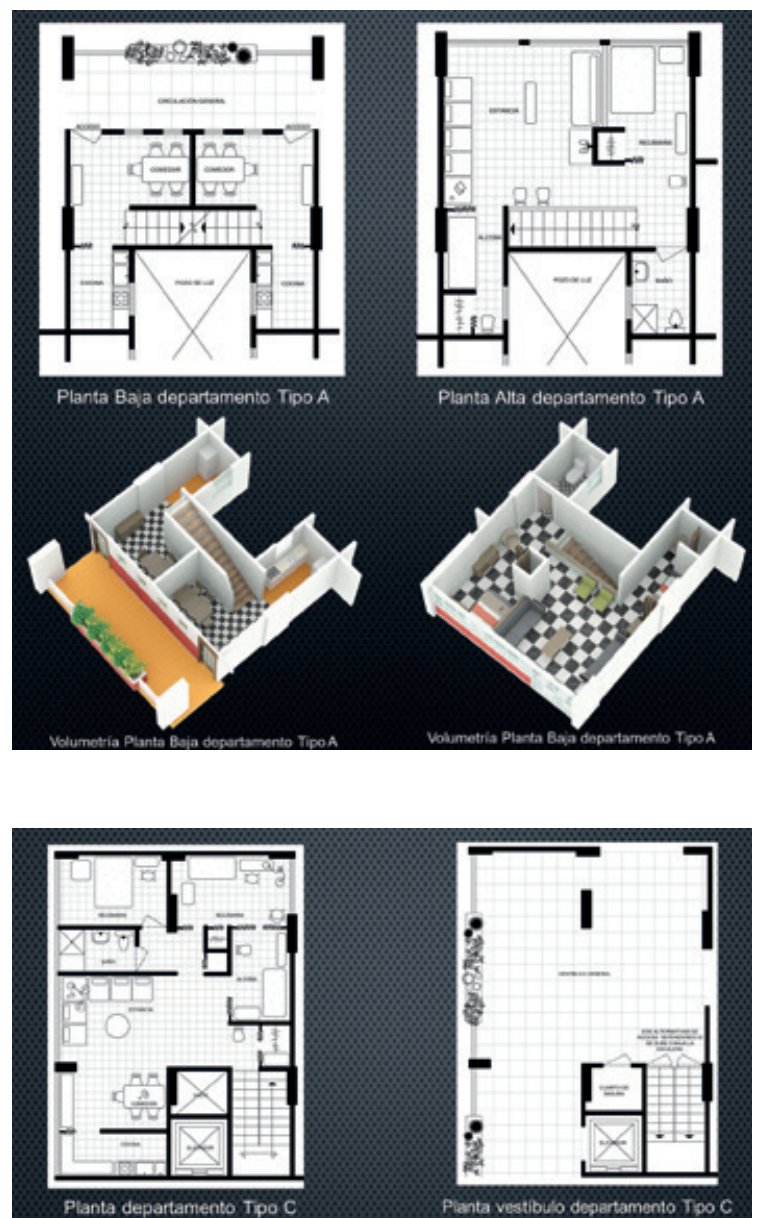

Planta departamento Tpo $\mathrm{C}$
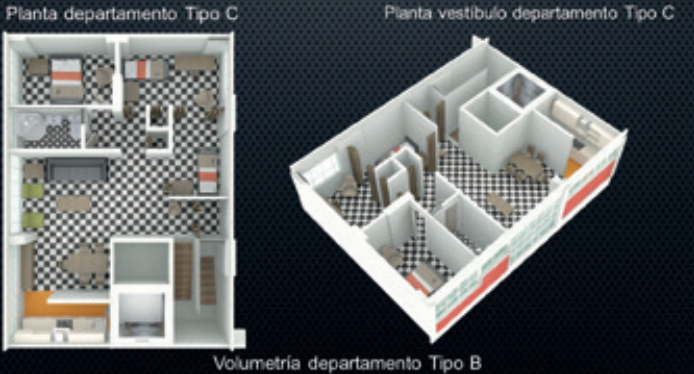

El departamento tipo A se ubica en las torres de 12 niveles. Se le llama "de pasillo" porque el acceso se realiza por un pasillo de circulación perimetral abierto [Figura 3], que comunica con los ascensores que llegan desde la planta baja del CUPA. Tiene $48 \mathrm{~m}^{2}$ de área. Se desarrolla en dos niveles; en el de acceso se ubica comedor y cocina, en el siguiente se localiza el baño, estancia y recámaras [Figura 4]. Los ventanales de fachada permiten la entrada de luz y aire naturales al interior de todos los locales de la vivienda.

Los resultados de las encuestas [Tabla 5] y su comparativa con la distribución de la primera tipología analizada, revelan que el diseño y proporción de las ventanas ayuda a reducir la transmisión del virus al interior; otorgan visuales panorámicas de la ciudad y jardines interiores del CUPA, dado que las torres cuentan con la altura necesaria para lograr esas perspectivas [Figura 8]. Asimismo, al tener dos niveles en este tipo de vivienda es posible realizar simultáneamente actividades laborales dentro de la casa.

El departamento tipo B - C, se localiza en los edificios de 12 niveles, su área es de $80 \mathrm{~m}^{2}$ y se le conoce como "de esquina" porque se localiza justamente en la esquina de los pasillos de circulación junto a los ascensores. Cuenta con una escalera que comunica la vivienda con el pasillo de acceso y se desarrolla en un solo nivel donde se encuentran todos los locales [Figura 5]. Los resultados de las encuestas [Tabla 5] y su comparativa con el departamento revelan que esta tipología posee las mismas cualidades interiores que el tipo A: iluminación, ventilación y visuales. Sin embargo, al desarrollarse en un solo nivel, la separación entre las actividades laborales y de habitar no se da con la misma claridad que en el caso anterior.

El departamento tipo $D$ es conocido coloquialmente como "del B, D ○ F", se localiza en las torres de departamentos con orientación norte-sur y recibe las nomenclaturas señaladas. Ligan, a manera de puentes, las cuatro torres oriente-poniente, generando la forma en zig-zag y el trazo á redent, característico del conjunto [Figura 2]. Esta tipología tiene una extensión de $110 \mathrm{~m}^{2}$ que se desarrolla en dos niveles. En el acceso se localiza el comedor, cocina y una estancia. En el siguiente nivel se ubica el baño, la sala y tres recámaras [Figura 6].

Los resultados de las encuestas [Tabla 5] y su comparativa con el diseño de la vivienda muestran que este tipo de departamento cuenta con los mismos atributos de diseño que el tipo A. Adicionalmente, al tener dimensiones considerablemente mayores, es posible separar con mayor facilidad el área que se destinará como la oficina dentro de casa.

Por último, el departamento tipo E es el único prototipo habitacional que se desarrolla en edificio de tres niveles; razón por la cual los habitantes le conocen coloquialmente como "chiquito", haciendo alusión a la escala del inmueble. A diferencia de las torres, aquí no hay ascensores ni pasillos de circulación; la escala de los inmuebles es visiblemente menor. Estos departamentos tienen una superficie de $57 \mathrm{~m}^{2}$ y se desarrollan en un solo nivel [Figura 7]. 
Tabla 5

Tabulación de las respuestas

recabadas para evaluar los posibles

elementos de diseño interior para

abatir transmisión aérea del COVID en

las cuatro tipologías habitacionales

del CUPA. Las opciones que tuvieron

mayor cantidad de menciones por parte

de los entrevistados se resaltan para

facilitar su identificación

Fuente: Elaboración del autor (2021).

\begin{tabular}{|c|c|c|c|c|c|c|c|c|c|}
\hline \multirow{2}{*}{\multicolumn{2}{|c|}{\begin{tabular}{|c|} 
Habitar el CUPA durante el COVID \\
Interior en las cuatro tipologías de vivienda
\end{tabular}}} & \multicolumn{2}{|c|}{$\begin{array}{c}\text { Vivienda tipo A } \\
\text { (145 cuestionarios) }\end{array}$} & \multicolumn{2}{|c|}{$\begin{array}{l}\text { Vivienda tipo B-C } \\
\text { (58 cuestionarios) }\end{array}$} & \multicolumn{2}{|c|}{$\begin{array}{l}\text { Vivienda tipo D } \\
\text { (36 cuestionarios) }\end{array}$} & \multicolumn{2}{|c|}{$\begin{array}{l}\text { Vivienda tipo E } \\
\text { (52 cuestionarios) }\end{array}$} \\
\hline & & Rptas & $\%$ & Rptas & $\%$ & Rptas & $\%$ & Rptas & $\%$ \\
\hline \multirow{2}{*}{$\begin{array}{l}\text { 1. ¿Las ventanas de tu } \\
\text { departamento permiten } \\
\text { ventilar todos los } \\
\text { cuartos? }\end{array}$} & a. Sí & 131 & 90,34482759 & 51 & 87,93103448 & 34 & 94,44444444 & 50 & 96,15384615 \\
\hline & b. No & 14 & 9,655172414 & 7 & 12,06896552 & 2 & 5,555555556 & 2 & 3,846153846 \\
\hline \multirow{5}{*}{$\begin{array}{l}\text { 2. ¿Qué han significa- } \\
\text { do para ti las ventanas } \\
\text { de tu casa durante el } \\
\text { confinamiento? }\end{array}$} & $\begin{array}{l}\text { a. Me han ayuda- } \\
\text { do a mantenerme } \\
\text { relajado(a) }\end{array}$ & 32 & 22,06896552 & 12 & 20,68965517 & 6 & 16,66666667 & 12 & 23,07692308 \\
\hline & $\begin{array}{l}\text { b. Me sirven } \\
\text { para concentrar- } \\
\text { me más mientras } \\
\text { trabajo }\end{array}$ & 21 & 14,48275862 & 10 & 17,24137931 & 2 & 5,555555556 & 0 & 0 \\
\hline & $\begin{array}{l}\text { c. Me siento pri- } \\
\text { vilegiado de tener } \\
\text { estas ventanas } \\
\text { con las visuales } \\
\text { hacia la ciudad o } \\
\text { jardines interiores } \\
\text { del CUPA } \\
\end{array}$ & 89 & 61,37931034 & 36 & 62,06896552 & 28 & 77,77777778 & 8 & 15,38461538 \\
\hline & $\begin{array}{l}\text { d. Me molestan } \\
\text { porque no tengo } \\
\text { privacidad }\end{array}$ & 3 & 2,068965517 & 0 & 0 & 0 & 0 & 28 & 53,84615385 \\
\hline & $\begin{array}{l}\text { e. Me resultan } \\
\text { indiferentes }\end{array}$ & 0 & 0 & 0 & 0 & 0 & 0 & 4 & 7,692307692 \\
\hline \multirow{2}{*}{$\begin{array}{l}\text { 3. ¿Debes trabajar } \\
\text { desde casa? }\end{array}$} & a. Sí & 80 & 55,17241379 & 41 & 70,68965517 & 22 & 61,11111111 & 31 & 59,61538462 \\
\hline & b. No & 65 & 44,82758621 & 17 & 29,31034483 & 14 & 38,88888889 & 21 & 40,38461538 \\
\hline \multicolumn{10}{|c|}{ En caso de trabajar desde casa } \\
\hline \multirow{2}{*}{$\begin{array}{l}\text { 1. ¿Has tenido que } \\
\text { realizar adaptaciones al } \\
\text { interior de tu casa para } \\
\text { poder trabajar desde } \\
\text { ahí? }\end{array}$} & a. Sí & 26 & 17,93103448 & 16 & 27,5862069 & 2 & 5,555555556 & 14 & 26,92307692 \\
\hline & b. No & 119 & 82,06896552 & 42 & 72,4137931 & 34 & 94,44444444 & 38 & 73,07692308 \\
\hline \multirow{4}{*}{$\begin{array}{l}\text { 2. ¿Qué tipo de } \\
\text { adaptaciones has } \\
\text { realizado? }\end{array}$} & $\begin{array}{l}\text { a. Sólo cambios } \\
\text { de mobiliario }\end{array}$ & 79 & 54,48275862 & 48 & 82,75862069 & 25 & 69,44444444 & 35 & 67,30769231 \\
\hline & $\begin{array}{l}\text { b. Nuevos } \\
\text { cuartos }\end{array}$ & 3 & 2,068965517 & 3 & 5,172413793 & 0 & 0 & 2 & 3,846153846 \\
\hline & $\begin{array}{l}\text { c. Redistribuir los } \\
\text { cuartos dentro de } \\
\text { la vivienda }\end{array}$ & 6 & 4,137931034 & 0 & 0 & 11 & 30,55555556 & 5 & 9,615384615 \\
\hline & d. Ninguno & 57 & 39,31034483 & 7 & 12,06896552 & 0 & 0 & 10 & 19,23076923 \\
\hline \multirow{2}{*}{$\begin{array}{l}\text { 3. ¿La distribución } \\
\text { de tu departamento te } \\
\text { permite realizar plena- } \\
\text { mente tus actividades } \\
\text { laborales dentro de tu } \\
\text { casa? }\end{array}$} & a. Sí & 118 & 81,37931034 & 18 & 31,03448276 & 34 & 94,44444444 & 14 & 26,92307692 \\
\hline & b. No & 27 & 18,62068966 & 40 & 68,96551724 & 2 & 5,555555556 & 38 & 73,07692308 \\
\hline \multirow{2}{*}{$\begin{array}{l}\text { 4. ¿Puedes seguir } \\
\text { realizando plenamente } \\
\text { las actividades que } \\
\text { realizabas dentro de } \\
\text { tu casa antes de la } \\
\text { pandemia? }\end{array}$} & a. Sí & 118 & 81,37931034 & 21 & 36,20689655 & 34 & 94,44444444 & 14 & 26,92307692 \\
\hline & b. No & 27 & 18,62068966 & 37 & 63,79310345 & 2 & 5,555555556 & 38 & 73,07692308 \\
\hline
\end{tabular}




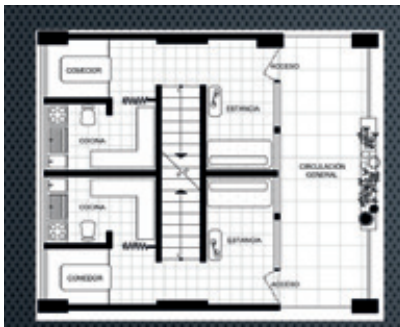

Planta baja departamento Tipo $D$

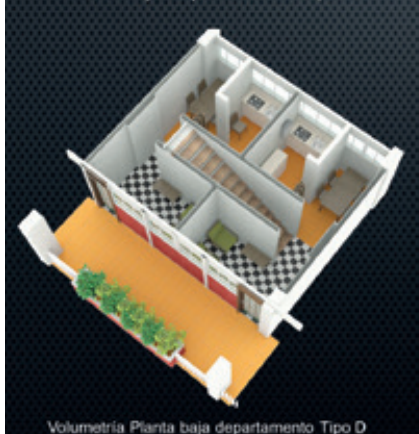

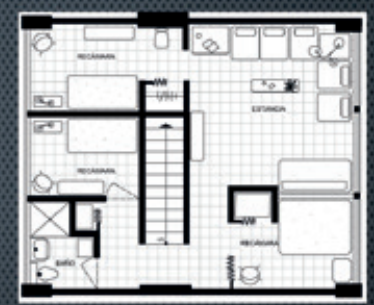

Planta ata departamento Tpo D

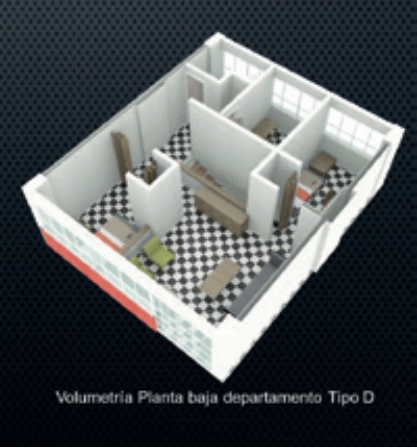

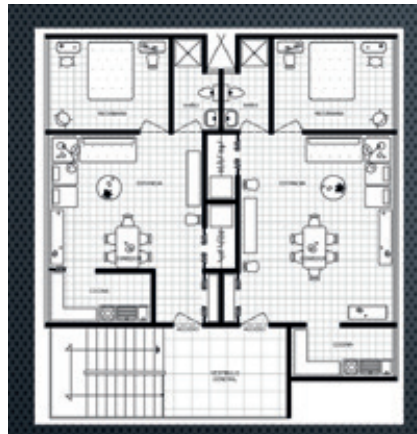

Planta departamento Tipo $\mathrm{E}$

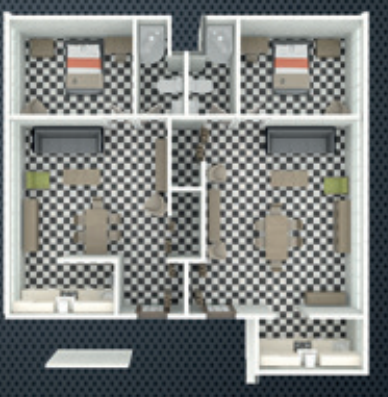

Voumetria Planta departamento Tpo $\mathrm{E}$

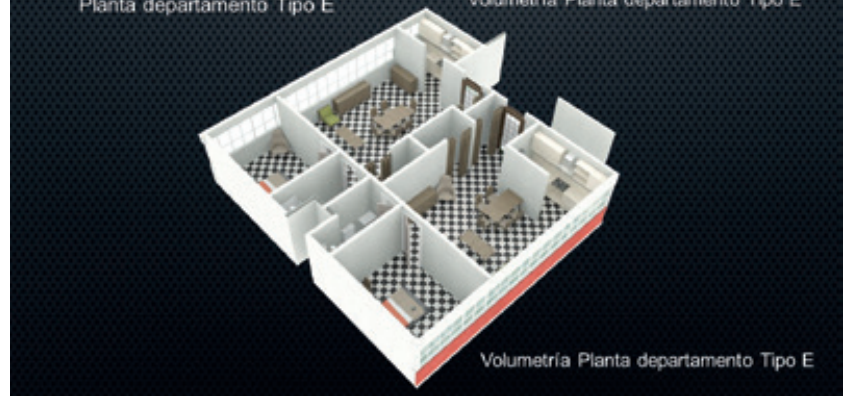

Figura 6

Lámina con planta

arquitectónica

y volumetría,

departamento tipo $D$.

Fuente: elaboración de

Raúl Cerezo (2021).

Figura 7

Lámina con planta

arquitectónica

y volumetría,

departamento tipo $\mathrm{E}$.

Fuente: elaboración de

Raúl Cerezo (2021).

\section{DISCUSIÓN}

Los resultados de las encuestas [Tabla 5], y su contraste con el diseño volumétrico de la vivienda, demuestran que en este tipo de departamento la ventana corrida de la fachada permite la entrada de luz y aire naturales permanentemente, al igual que en el resto de las tipologías habitacionales. Sin embargo, al estar en edificio de baja altura, no le es posible contar con visuales hacia jardines, mucho menos a la ciudad; su desarrollo en un solo nivel impide separar actividades, como sí ocurre con las tipologías A y D.

Los comercios disponibles en el CUPA y que en la actualidad dan testimonio de los principios de diseño que identifican a las supermanzanas de habitación colectiva han resultado suficientes para abastecer productos básicos durante la pandemia, en el sector de habitantes encuestados. Se han consolidado como una opción de abasto viable que ha garantizado el suministro de alimentos y medicamentos por lo que no hay necesidad de desplazarse fuera de la unidad habitacional, o a zonas lejanas de la ciudad, para adquirirlos.

Los espacios comunes ayudan a reducir el estrés laboral ocasionado por el hecho de vivir y trabajar en el mismo lugar. En igual sentido, los pasillos perimetrales de acceso a viviendas en torre han resultado útiles no solamente por su función de conexión y circulación, sino también porque se han constituido en espacios donde la gente puede caminar libremente con fines recreativos sin temor de contagio. Al estar abiertos, permiten la circulación de aire y, a su vez, la altura de los edificios permite disfrutar las visuales que ofrecen hacia la ciudad o los jardines interiores de la unidad [Figura 8]. Los jardines son sitios en los que, a pesar del conflicto vecinal derivado de su uso para pasear mascotas, 


\section{CONCLUSIONES}

es posible circular sin el riesgo de contagio que presentan espacios colectivos cerrados sin ventilación. Paulatinamente las áreas verdes han sido revaloradas por los moradores como necesarias extensiones de la vivienda durante el confinamiento obligado por la pandemia.

Sobre los cuatro tipos de vivienda analizados, se puede afirmar que las condiciones son variables, sin embargo, la materialización de los principios del diseño moderno en grandes ventanales que permiten la entrada de iluminación y ventilación naturales, así como visuales que se apropian de elementos paisajísticos -panorámicas de la ciudad y jardines- en las torres de departamentos, generan atributos del diseño arquitectónico que son claramente reconocidos por los habitantes.

Al comparar los resultados mostrados en la Tabla 5 con el diseño de las tipologías habitacionales, se observa que todos los tipos de departamentos cuentan con ventilación natural al interior de todos sus locales. Las necesarias barreras físicas para la separación de actividades laborales, familiares y de habitación se dan en las tipologías de departamento con dos niveles. En contraste, los dos tipos de departamento que se desarrollan en un solo nivel obligan a que las actividades se mezclen al interior de la vivienda.

La vivienda colectiva de la modernidad conformó un paradigma de habitación que durante la actual pandemia recobra validez a partir de su diseño que resulta útil para disminuir la transmisión de un virus que se contagia por vía aérea. Los resultados de la investigación que aquí se presenta, demuestran que el ideal moderno de conformar espacios sanos, higiénicos y ventilados debe retomarse a partir de la utilidad que hasta el momento ha evidenciado en casos como el CUPA.

El conjunto estudiado tiene una densidad poblacional alta, sin embargo, de acuerdo con los datos oficiales del gobierno de la Ciudad, no ha registrado contagios desde marzo de 2020, cuando inició la pandemia en México a pesar de tener enfrente a un hospital que atiende casos de COVIDI9. Se ubica en una zona privilegiada de la ciudad, con acceso a supermercados, parques, servicios, centros comerciales, de trabajo y a todos los sistemas de transporte público, atributos que, en conjunción con las amenidades de las que dispone el CUPA, han sido determinantes para reducir desplazamientos no esenciales de sus habitantes y, de esa forma, contribuir a la reducción de contagios.

Este prodigioso conjunto habitacional, paradigmático en América Latina, una vez más demuestra las virtudes de su diseño urbano - arquitectónico: lo hace ahora desde una visión post COVID. Sus espacios colectivos y de circulación están abiertos con lo que permanentemente se encuentran ventilados; su amplitud propicia, de manera natural, la deseable sana distancia que permite evitar aglomeración de usuarios en espacios compartidos. Sus jardines, que ocupan el $80 \%$ del área de desplante del terreno rodeando los edificios, inte- 


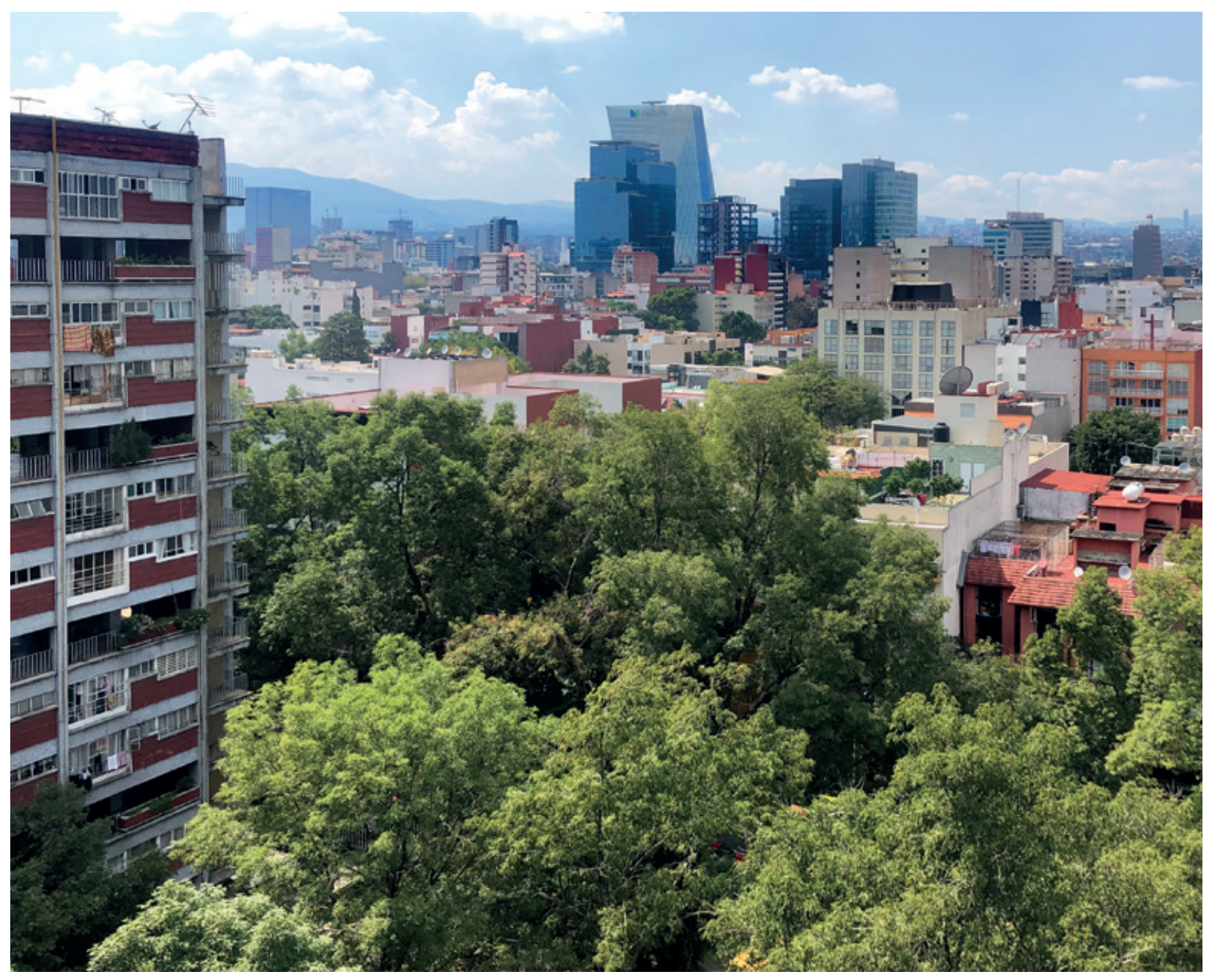

\section{Figura 8}

Visuales desde

los pasillos

de circulación

CUPA.

Fuente: Fotografia

del autor (2020). gran generosas visuales panorámicas desde las viviendas [Figura 8] y son, además, espacios de recreación y circulación seguros para los moradores.

El interés de los CIAM, y particularmente el de 1933, por planificar la ciudad a partir de supermanzanas de habitación, que propugnaba por una vivienda higiénica con entrada de luz y ventilación naturales para disminuir los contagios de enfermedades, como la tuberculosis, debe ser retomado para formar parte de la respuesta que desde la arquitectura y el urbanismo se genere con miras a establecer nuevos paradigmas de diseño enfocados en disminuir las cadenas de transmisión aérea del coronavirus.

Las lecciones del pasado resultan útiles en la conformación de nuevos derroteros para el diseño de espacios salubres en medio de una normalidad que posiblemente llegó para quedarse. El CUPA demuestra que es posible retomar esas lecciones y aportar a la conformación de paradigmas de diseño que se requieren en el presente como una respuesta obligada a la pandemia desde la arquitectura y el urbanismo. 


\section{REFERENCIAS BIBLIOGRÁFICAS}

Congresos Internacionales de Arquitectura Moderna (CIAM) (1933). Carta de Atenas.

DE GARAY, G. (2004). Modernidad habitada: Multifamiliar Miguel Alemán ciudad de México, 1949-1999. México: Instituto Mora.

DUHAU, E. Y GIGLIA, A. (2004). Las reglas del desorden. Habitar la metrópoli. México: Siglo XXI Editores, UAM Azcapotzalco.

Gobierno de la Ciudad de México (12 de octubre de 2020). Mapa COVID Ciudad de México. Recuperado de https://datos.cdmx.gob.mx/pages/covid19/ GÓMEZ PORTER, P. F. (2020). Gestión de unidades habitacionales de la modernidad en México.

Gremium, 7(13), 39-50.

INEGI (2016). Inventario Nacional de Vivienda 2016. Obtenido de https:// www.inegi.org.mx/app/mapa/inv/

MONTANER, J. M. (2015). La arquitectura de la vivienda colectiva. Políticas y proyectos en la ciudad contemporánea. Barcelona: Reverté.

MORAWSKA, L. Y CAO J. (2020). Airborne transmission of SARS-CoV-2: The world should face the reality. Environment International, 139.

MUXí MARTíNEZ, Z. (2020). Viviendo en pandemia. Reflexiones en torno al habitar y la salud. Topofilia, Revista de Arquitectura, Urbanismo y Territorios, (21), 2-13.

PANI, D. M. (1950). Centro urbano "Presidente Alemán". Revista Arquitectura México, (30), 263-275.

PANI, D. M. (1952). Los multifamiliares de pensiones. México: Arquitectura.

SAMBRICIO, C. (2012). Ciudad y vivienda en América Latina 1930-1960. Madrid: Lampreave.

UNESCO (1972). Convención del patrimonio mundial, cultural y natural. París: Organización de las Naciones Unidas para la Educación, la Ciencia y la Cultura.

UNESCO (2008). Directrices prácticas de aplicación de la convención del patrimonio mundial, cultural y natural. París: Organización de las Naciones Unidas para la Educación, la Ciencia y la Cultura.

UNESCO (12 de octubre de 2020). World Heritage Centre. En: Obra arquitectónica de Le Corbusier - Contribución excepcional al Movimiento Moderno. Recuperado de https://whc.unesco.org/en/list/1321

VILLAVICENCIO, J. (2006). Conjuntos y unidades habitacionales en la Ciudad de México: en busca de espacios sociales y de integración barrial. México: Red Nacional de Investigación Urbana. 